The J ournal of Animal \& Plant Sciences, 31(3): 2021, Page: 773-781 ISSN (print): 1018-7081; ISSN (online): 2309-8694

\title{
MODELING AND FORECASTING CHERRY PRODUCTION IN TURKEY
}

\author{
M. Akın¹, S. P. Eyduran², Ş. Çelik ${ }^{3}$, P. Aliyev ${ }^{4}$, S. Aykol ${ }^{4}$ and E. Eyduran ${ }^{4}$ \\ ${ }^{1}$ Igdir University, Agricultural Faculty, Department of Landscape Architecture, Igdir, Turkey \\ ${ }^{2}$ Igdir University, Agricultural Faculty, Department of Horticulture, Igdir, Turkey \\ ${ }^{3}$ Bingol University, Agricultural Faculty, Department of Animal Science, Bingol, Turkey \\ ${ }^{4}$ Igdir University, Faculty of Economics and Administrative Sciences, Department of Business Administration, Igdir, \\ Turkey \\ Corresponding Author's Email: senolcelik@bingol.edu.tr
}

\begin{abstract}
In this article, the yearly cherry production (in tonnes) data of Turkey for the period of 1961-2019 were used in order to model and forecast cherry production for the period 2020-2025 using Autoregressive Integrated Moving Average (ARIMA) models. Time series data for cherry were found to be non-stationary at the level and hence the first differences of the series were taken to obtain stationary time series before performing the time series modeling. The Box-Jenkins approach was employed and the ARIMA $(1,1,1)$ model was determined to be the most appropriate among the several ARIMA models for the data. The model forecasted the increase in cherry production for 2020-2025 period in Turkey from 66.4076 to 72.6028 tonnes (approximately $1.8 \%$ annual growth rate in production). The forecasts for the between 2020 and 2025 will access from 696351 to 887609 tonnes in logarithmic transformed new series (ARIMA $(0,1,1)$ ). The findings of this study may assist policy makers in developing better strategies for sustainable cherry production.
\end{abstract}

Key Words: Cherry production, ARIMA, Forecasting, Stationary, Turkey

https://doi.org/10.36899/JAPS.2021.3.0267

Published online November 09, 2020

\section{INTRODUCTION}

Cherries, containing beneficial substances against heart diseases, cancers, diabetes, are taxonomically categorized in the genus Primus, belonging to Rosaceae family, and have two main types: sweet and sour cherries (Ferretti et al., 2010). Turkey is leading in the world sweet cherry production, followed by the USA, China, Ukraine, Poland and Chile (Donoso et al., 2019). Turkey has a high biodiversity in cherry germplasm, is also the leading exporter of sweet cherries (Prunus avium L.) which are primarily cultivated in Aegean, Marmara, Mediterranean and Black Sea regions. Conventional application methods are generally adopted for cherry production in Turkey; however, modern cherry orchards with high density planting systems have been created in recent years using promising cultivars, rootstocks and application methods (Demirsoy et al., 2017) to meet increasing domestic and foreign demands. Production of cherry as an export item, among all horticultural crops, is a remarkable activity in Turkish economy (Bal and Cercinli, 2013). Therefore, forecasting studies for developing better future agricultural policies for cherry, which has antioxidant, anti-inflammatory and anticancer properties (Ferretti et al., 2010), are important for Turkey.

Forecasting is stated as a technique of defining events whose real results are not yet known (Gowri and Kawitha, 2016). For forecasting purposes, time series methods handle the past trend of a variable, such as production amount, harvest area, and price, to forecast its future values (Hamjah, 2014). Among those, ARIMA and exponential smoothing time series methods have been used widely for forecasting (Eyduran et al., 2020).

The traditional time series models such as ARIMA and exponential smoothing methods have received much attentions among researchers for forecasting production amounts of agricultural crops i.e. apple (Sharma et al., 2014), strawberry (Akin and Eyduran, 2017a), avocado (Akin and Eyduran, 2017b), grape (Eyduran and Akin, 2017a), groundnut (Borkar, 2016; Celik et al., 2017), apricot (Topuz et al., 2018), peach (Ullah et al., 2018), mandarin (Celik, 2019), pineapple (Hossain and Abdulla, 2015), banana (Hamjah 2014; Gowri and Kawitha, 2016; Hossain et al., 2016; Eyduran et al., 2020), pistachio, pistachio, walnut, hazelnut and almond (Celik, 2013), chestnut (Başer et al., 2018), soybean, sunflower and sesame (Karadas et al., 2017) in different countries of the world. On the other hand, the present literature of forecasting studies in horticultural crops is still insufficient. To the best of our knowledge, forecast of cherry production in Turkey has not yet been documented until now. Therefore, in the present work, cherry production amounts for the 19612019 period were evaluated to forecast cherry production for the 2020-2025 period in Turkey using ARIMA modeling. 


\section{MATERIALS AND METHODS}

The FAOSTAT (Food and Agriculture Organization Corporate Statistical Database) (FAO, 2018) database on annual production amounts of cherry for the 1961-2018 period and TURKSTAT (2019) data were used in order to forecast annual cherry production for the 2020-2025 period in Turkey using ARIMA models. Only the production amount in 2019 year was provided from TURKSTAT database.

The formal Box-Jenkins approach was employed to model and forecast the cherry production. Building an appropriate ARIMA model generally consists of three steps that include model identification, estimation of the parameters and diagnostic checking. In the model identification step, the model is estimated by addressing the stationarity problems, if any, of the data. For this purpose, autocorrelation and partial correlation functions were employed. In the second step, parameters of the models are estimated by the method of maximum likelihood. Finally, in the last step, the residuals were tested for normality and homoscedasticity.

Formulas of model fit statistics used to capture the top one among five ARIMA models denoted as $(1,1,0),(1,1,1),(0,1,1),(2,1,0)$ and $(0,1,2)$ are written as follows:

The predictive quality of the fitted methods was determined by coefficient of determination $\left(\mathrm{R}^{2}\right)$ and $\mathrm{BIC}$ (Bayesian information criterion). The BIC was recommended by Schwarz (1978) and defined as

$$
B=h\left(\hat{\sigma}_{e}^{2}\right)+k(n) / n
$$

where $\sigma_{e}^{2}$ is the error variance, $k$ is the number of parameters and $n$ is the length of time series.

The Root Mean Squared Error (RMSE) is expressed as follows (Willmott et al., 2009)

$$
\text { RMSE }=\sqrt{\frac{1}{n} \sum_{t=1}^{n}\left(y_{t}-\hat{y}_{t}\right)^{2}}
$$

Here $y_{\mathrm{t}}$ is realization, $y_{\tau}$ is forecast value and $n$ is number of out-of-sample forecast.

The Maximum Absolute Percentage Error is defined as

$M \quad=m \quad\left(\left|\frac{y_{t}-\hat{y}_{t}}{y_{t}}\right|\right) * 100, t=1,2, \ldots, n$
The predictive precision related to the methods applied for the study was measured by Stationary $\mathrm{R}^{2}$ (Pektas, 2013). The Stationary R-Squared statistic was used by Harvey (1989) and defined as follows:

$R_{S}^{2}=1-\frac{\sum_{t}\left(y_{\tau}-\hat{y}_{t}\right)^{2}}{\sum_{t}\left(\Delta y_{t}-\overline{\Delta y}\right)^{2}}$

where, $\Delta y_{\tau}$ is the differenced or transformed series.

The model having the highest $\mathrm{R}^{2}$ and $R_{S}^{2}$ and the smallest MAPE, MaxAPE, RMSE and BIC values was selected as the best ARIMA model. Annual production data in regards to the cherry was forecasted using IBM SPSS program.

\section{RESULTS}

The graph of annual cherry production amounts from the period 1961-2019 in Turkey is presented in Figure 1. An increasing trend was observed in Figure 1 which also indicated non-stationarity in cherry production time series.

The graphs of ACF (Autocorrelation Function) and PACF (Partial Autocorrelation Function) are given in Figure 2. Figure 2 reflected that most of lag numbers in ACF plot surpassed confidence limits and so the first difference of the non-stationary time series was taken to create stationary time series data.

Because, in ARIMA models, differencing is a significant stage as a technique of changing a nonstationary time series data into stationary one. Figure 3 presents ACF and PACF graphs of the first difference series. As seen from Figure 3, the first difference series of the cherry production data was found stationary.

Results of model fit statistics for 15 candidate ARIMA models are presented in Table 1. Among the evaluated models, the ARIMA $(1,1,1)$ was determined as the best Box-Jenkins model for forecasting cherry production in Turkey since it had the highest $\mathrm{R}^{2}$, the smallest MAPE, MaxAPE, RMSE and BIC values.

Besides, most of the other ARIMA models except for ARIMA $(1,1,1)$ were determined to have insignificant parameters statistically (data not reported). 


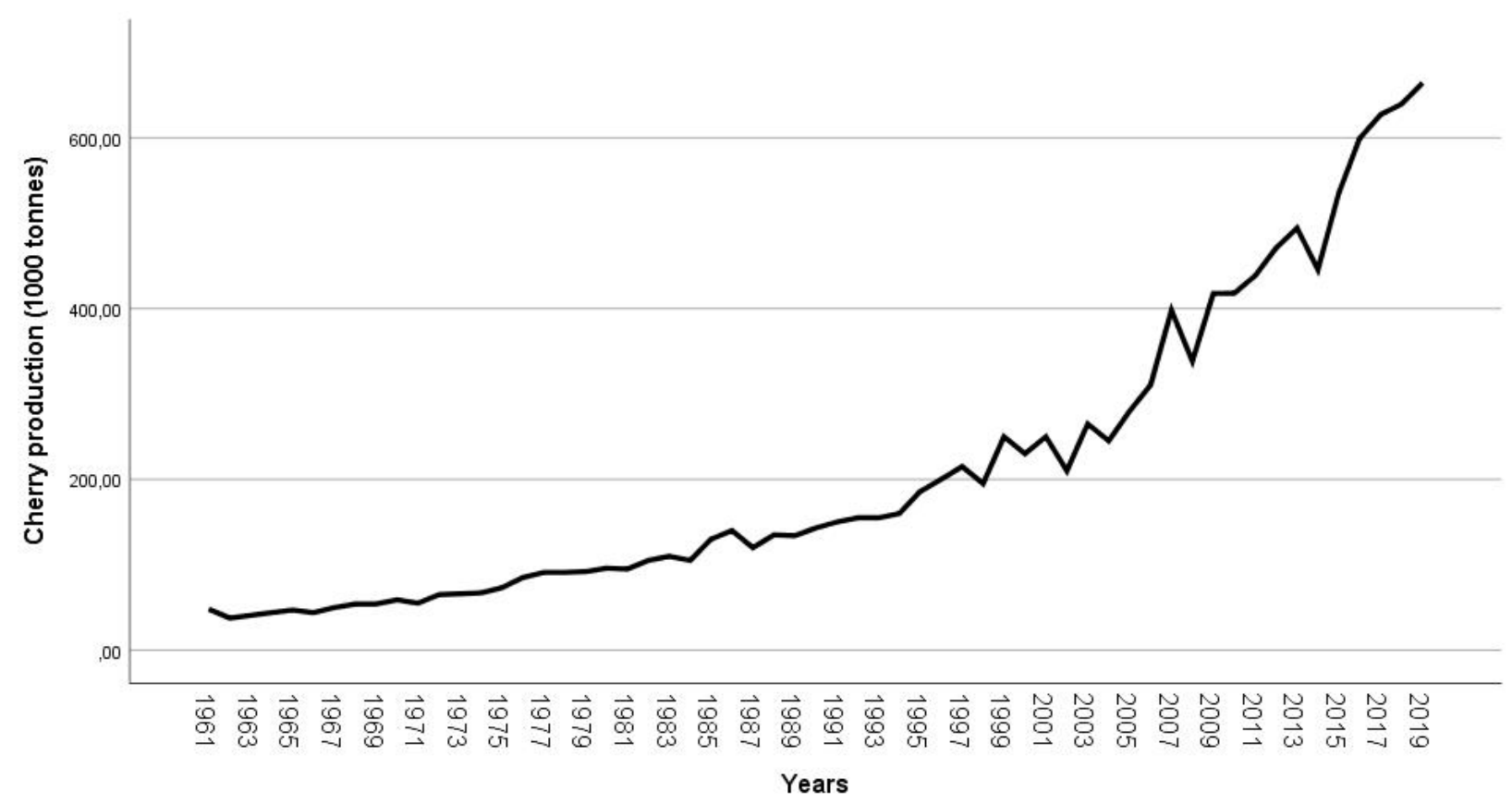

Figure 1. Graph of annual cherry production amounts (1000 tonnes) from the period 1961-2019 in Turkey
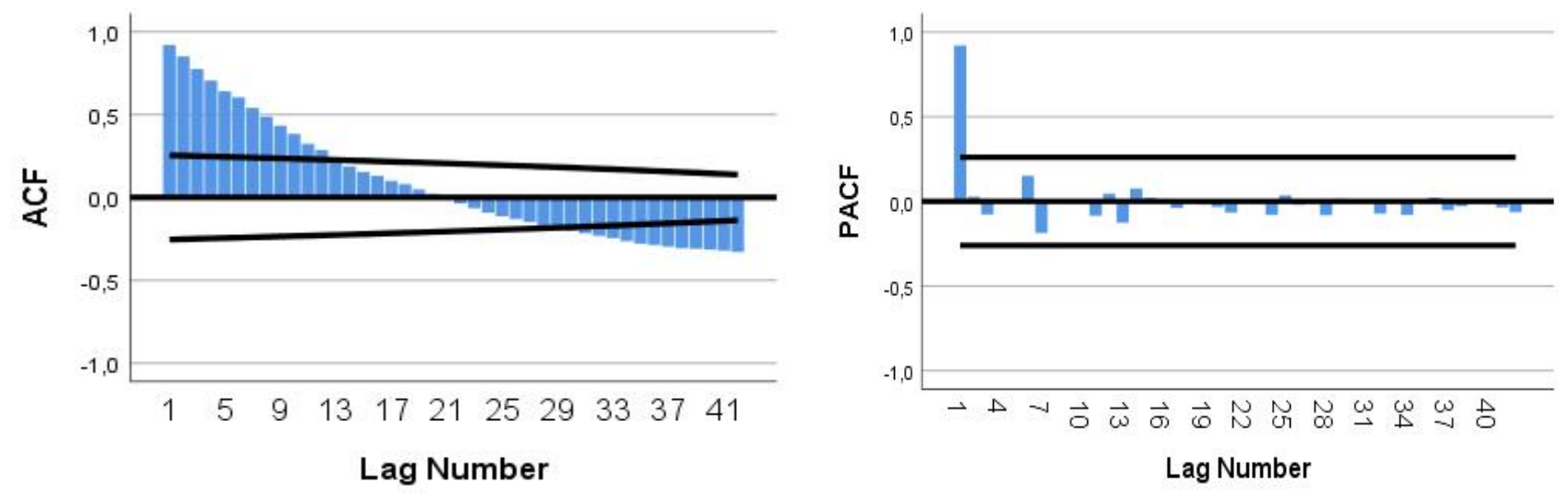

Figure 2. Graphs of ACF-PACF for cherry production

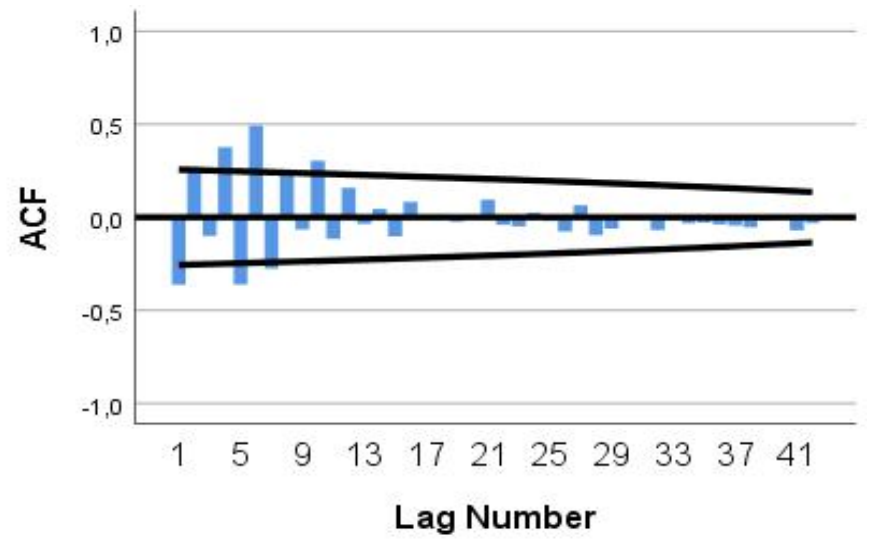

Figure 3. ACF-PACF graphs of the first difference series

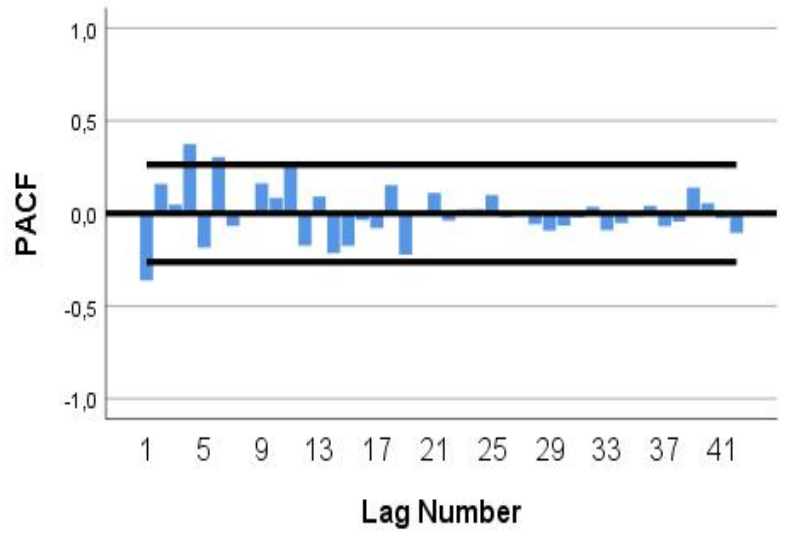


Table 1. Model fit statistics.

\begin{tabular}{lccccccc}
\hline Candidate ARIMA models & $\mathbf{R}^{\mathbf{2}}$ & Stationary $\mathbf{R}^{\mathbf{2}}$ & MAPE & MaxAPE & RMSE & BIC & $\begin{array}{c}\text { BIC } \\
\text { Rank }\end{array}$ \\
\hline ARIMA(1,1,0) & 0.978 & 0.132 & 12.084 & 56.003 & 26096 & 20.479 & 2 \\
ARIMA(0,1,1) & 0.977 & 0.092 & 12.107 & 55.991 & 26687 & 20.524 & 5 \\
ARIMA(1,1,1) & 0.980 & 0.214 & 10.603 & 55.734 & 25054 & 20.468 & 1 \\
ARIMA(2,1,0) & 0.979 & 0.153 & 11.046 & 55.923 & 26012 & 20.543 & 10 \\
ARIMA(0,1,2) & 0.979 & 0.159 & 10.965 & 55.845 & 25919 & 20.535 & 7 \\
ARIMA(2,1,2) & 0.978 & 0.206 & 11.255 & 61.394 & 25327 & 20.599 & 13 \\
ARIMA(2,1,1) & 0.979 & 0.210 & 10.629 & 59.714 & 25516 & 20.535 & 8 \\
ARIMA(1,1,2) & 0.981 & 0.253 & 10.402 & 64.333 & 24642 & 20.504 & 4 \\
ARIMA(0,2,1) & 0.976 & 0.660 & 9.315 & 45.987 & 27102 & 20.557 & 12 \\
ARIMA(1,2,0) & 0.968 & 0.536 & 9.453 & 44.640 & 31671 & 20.868 & 15 \\
ARIMA(0,2,2) & 0.983 & 0.751 & 8.925 & 39.860 & 24976 & 20.499 & 3 \\
ARIMA(2,2,0) & 0.972 & 0.598 & 9.480 & 42.255 & 29761 & 20.815 & 14 \\
ARIMA(1,2,1) & 0.983 & 0.748 & 8.881 & 41.960 & 24555 & 20.547 & 11 \\
ARIMA(2,2,1) & 0.983 & 0.750 & 8.984 & 41.984 & 24684 & 20.529 & 6 \\
ARIMA(1,2,2) & 0.983 & 0.748 & 8.879 & 41.979 & 24788 & 20.538 & 9 \\
\hline
\end{tabular}

The appropriateness of the first order ARIMA $(1,1,1)$ was tested by Ljung-Box test $(20.468, \mathrm{p}>0.05)$.
Significant parameters $(\mathrm{p}<0.01)$ obtained for the ARIMA $(1,1,1)$ model are presented in Table 2 .

Table 2. Estimated parameters of the ARIMA $(1,1,1)$ model.

\begin{tabular}{lrrrr}
\hline & Coefficient & Std Error & t value & \multicolumn{1}{c}{ Prob } \\
Constant & 10555.933 & 3025.035 & 3.414 & 0.001 \\
AR (1) & -0.947 & 0.082 & -11.546 & 0.001 \\
MA (1) & -0.791 & 0.158 & -5.019 & 0.001 \\
\hline
\end{tabular}

The ARIMA $(1,1,1)$ model can be written as

$y_{\tau}=\mu+\phi y_{\tau-1}+\theta e_{\tau-1}+e_{\tau}$

where $y_{\tau}$ is the time series, $\mu$ is the intercept term, $\phi$ is the AR coefficient and $\theta$ is the MA coefficient with $e_{\tau}$ being the residual or error term.

The fitted ARIMA $(1,1,1)$ model is:

$$
y_{\tau}=10555.933-0.947 y_{t-1}+0.791 e_{t-1}+e_{\tau}
$$

Figure 4 presents the ACF and PACF plots of residuals. These plots would help in diagnostics of residuals. No significant autocorrelation was observed in the residuals of the fitted model. After these findings, cherry production amounts for the period 2020-2025 were forecasted on the basis of the fitted ARIMA $(1,1,1)$ model. Table 3 presents $2020-2025$ cherry production forecasts. A very good fit was observed between the actual and the fitted values of cherry production (Figure 5). Forecasts reflected that an increase in cherry production from 664076 to 726028 tonnes would be expected.

As the best one among the evaluated models, ARIMA $(1,1,1)$ was tested in autocorrelation and heteroscedasticity. Durbin-Watson d statistic was found as 2.097 , very close to 2.000 , which means that there is no autocorrelation problem. To test heteroscedasticity case of the ARIMA (1,1,1), ARCH (autoregressive conditional heteroscedasticity) test was used $\left(\mathrm{nR}^{2}=10.636\right.$ and $\mathrm{p}<0.01$ ). To eliminate the heteroscedasticity problem, a logarithmic transformation was applied. After the logarithmic transformation, ARCH test was employed $\left(\mathrm{nR}^{2}=0.517\right.$ and $\left.\mathrm{p}=0.472>0.05\right)$, meaning that the problem was removed. ARIMA $(0,1,1)$ was found the as most suitable model for time series transformed logarithmically. The obtained new model's coefficients were significant $(\mathrm{p}<0.05)$. The forecasts for the period 2020-2025 will reach from 696351 to 887609 tonnes. 

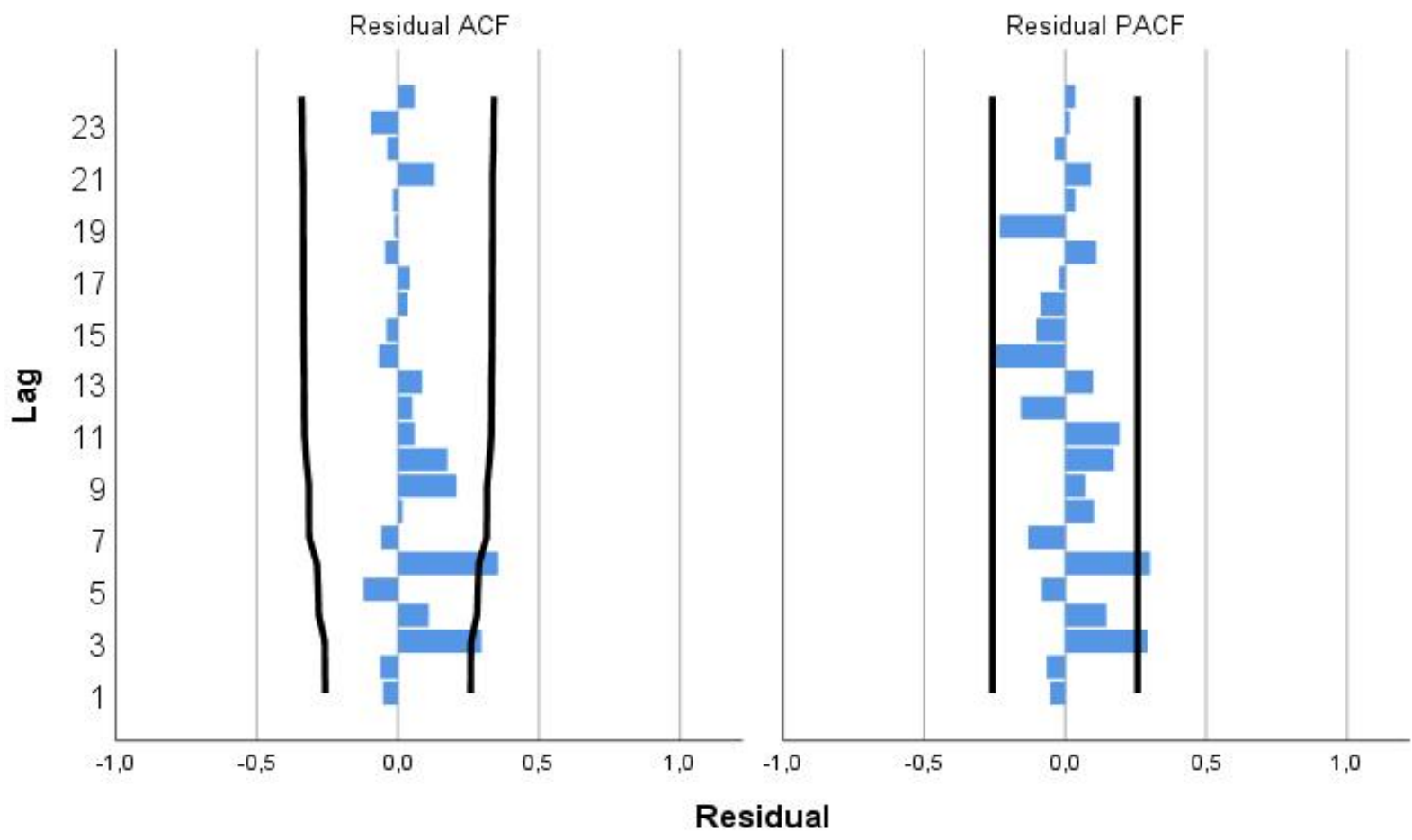

Figure 4. ACF and PACF graphs of residuals

Table 3. Cherry production forecasts (in tonnes) for the period 2020-2025 .

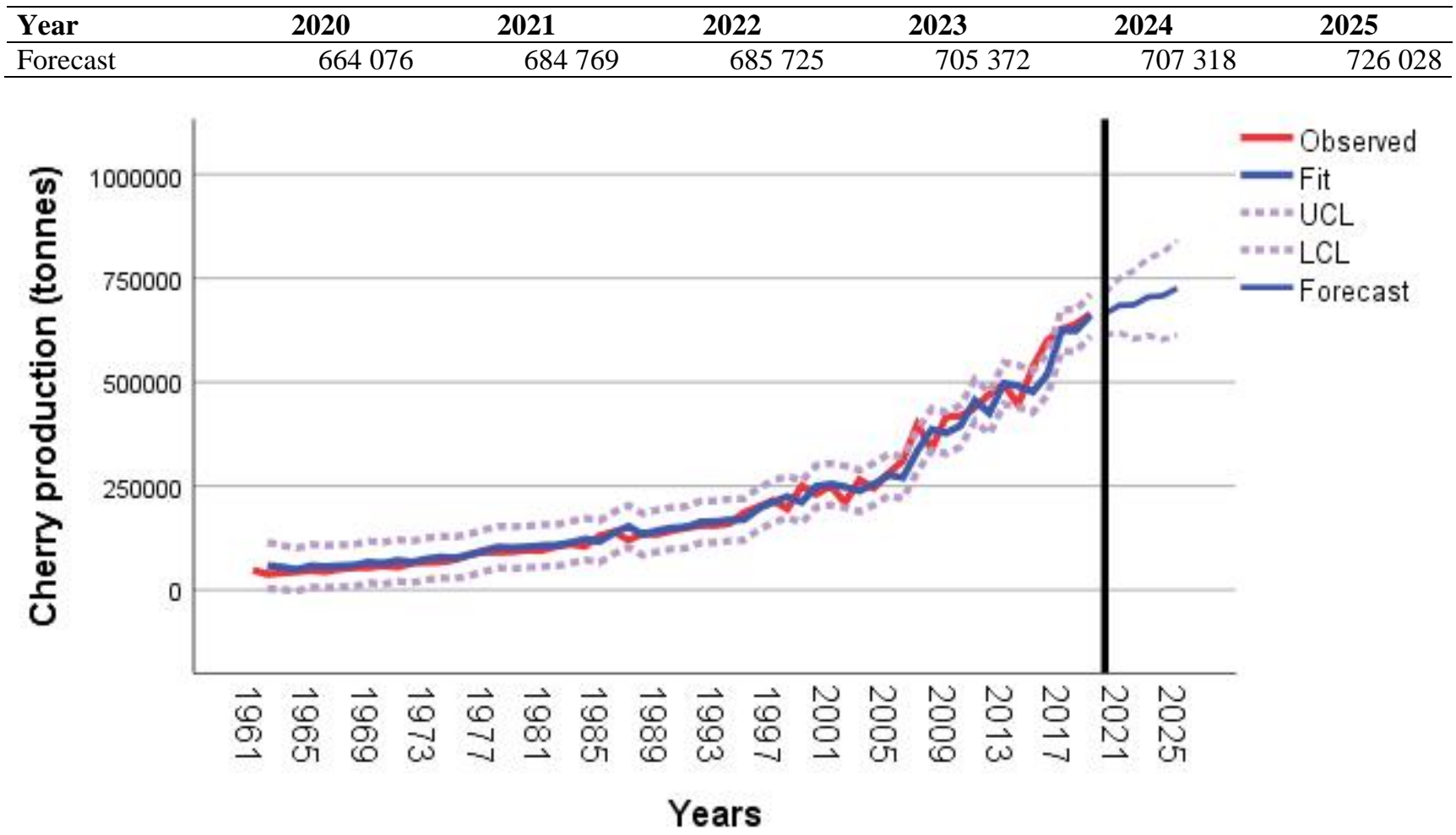

Figure 5. Observed and fitted series graph on cherry production

Figure 6 presents ACF and PACF graphs of the first difference transformation logarithmic series.
For transformation logarithmic series, results of model fit statistics for 15 candidate ARIMA models are 
given in Table 4. Among the evaluated models, the ARIMA $(1,1,0)$ was determined as the best Box-Jenkins

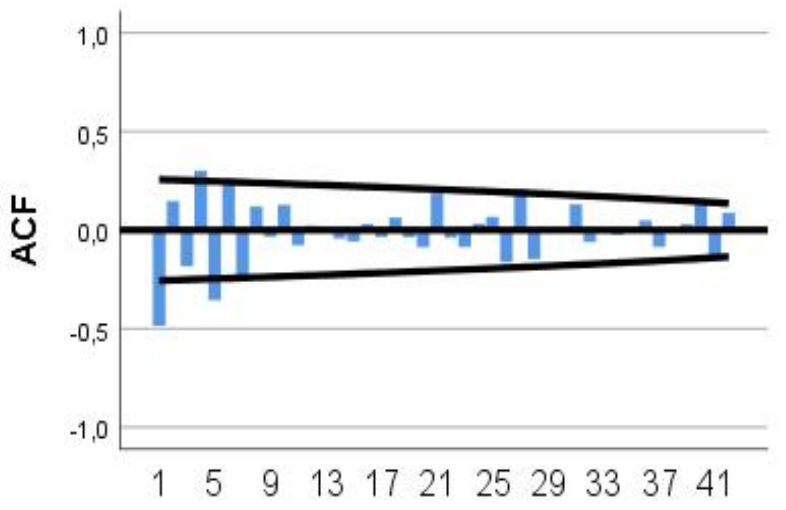

Lag Number model for forecasting cherry production in Turkey since it had the smallest BIC values.

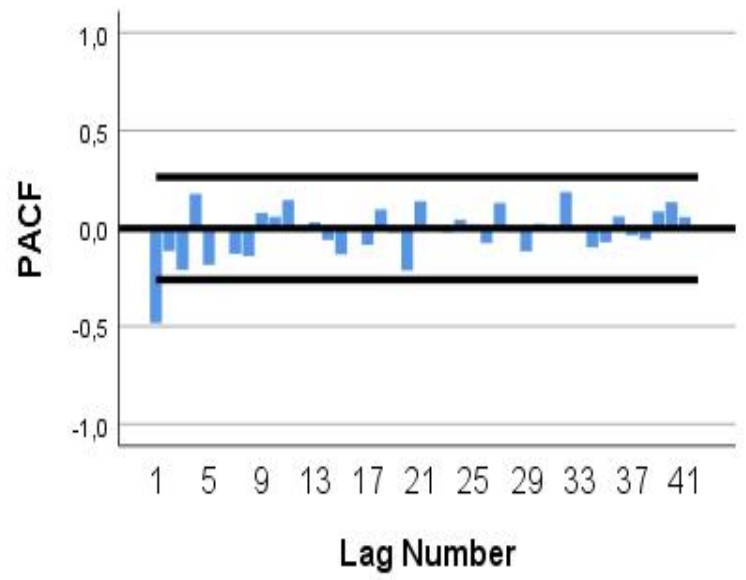

Figure 6. ACF-PACF graphs of the first difference of transformation logarithmic series

Table 4. Model fit statistics for transformation logarithmic series.

\begin{tabular}{lccccccc}
\hline Candidate ARIMA models & $\mathbf{R}^{\mathbf{2}}$ & Stationary $\mathbf{R}^{\mathbf{2}}$ & MAPE & MaxAPE & RMSE & BIC & $\begin{array}{c}\text { BIC } \\
\text { Rank }\end{array}$ \\
\hline ARIMA(1,1,0) & 0.988 & 0.231 & 0.581 & 2.765 & 0.092 & -4.633 & 2 \\
ARIMA(0,1,1) & 0.989 & 0.276 & 0.548 & 2.779 & 0.089 & -4.694 & 1 \\
ARIMA(1,1,1) & 0.989 & 0.275 & 0.543 & 2.778 & 0.090 & -4.604 & 4 \\
ARIMA(2,1,0) & 0.988 & 0.249 & 0.555 & 2.771 & 0.092 & -4.569 & 5 \\
ARIMA(0,1,2) & 0.989 & 0.275 & 0.545 & 2.778 & 0.090 & -4.605 & 3 \\
ARIMA(2,1,2) & 0.989 & 0.308 & 0.553 & 2.778 & 0.090 & -4.475 & 8 \\
ARIMA(2,1,1) & 0.989 & 0.286 & 0.545 & 2.777 & 0.090 & -4.532 & 7 \\
ARIMA(1,1,2) & 0.989 & 0.297 & 0.546 & 2.777 & 0.089 & -4.547 & 6 \\
ARIMA(0,2,1) & 0.981 & 0.596 & 0.707 & 3.059 & 0.113 & -4.218 & 12 \\
ARIMA(1,2,0) & 0.975 & 0.480 & 0.832 & 3.035 & 0.128 & -3.964 & 15 \\
ARIMA(0,2,2) & 0.985 & 0.686 & 0.622 & 3.054 & 0.101 & -4.379 & 9 \\
ARIMA(2,2,0) & 0.978 & 0.539 & 0.748 & 3.044 & 0.122 & -3.996 & 14 \\
ARIMA(1,2,1) & 0.985 & 0.673 & 0.640 & 3.054 & 0.103 & -4.340 & 10 \\
ARIMA(2,2,1) & 0.985 & 0.679 & 0.630 & 3.054 & 0.103 & -4.267 & 11 \\
ARIMA(1,2,2) & 0.984 & 0.661 & 0.684 & 3.053 & 0.106 & -4.214 & 13 \\
\hline
\end{tabular}

The appropriateness of the first order ARIMA $(0,1,1)$ was tested by Ljung-Box test $(15.692, p>0.05)$. Significant parameters $(\mathrm{p}<0.01)$ obtained for the ARIMA $(0,1,1)$ model are given in Table 5 .

Table 5. Estimated parameters of the ARIMA $(0,1,1)$ model.

\begin{tabular}{lrrrr}
\hline & Coefficient & Std Error & t value & \multicolumn{1}{c}{ Prob } \\
\hline Constant & 0.049 & 0.003 & 14.430 & 0.001 \\
MA (1) & 0.716 & 0.100 & 7.183 & 0.001 \\
\hline
\end{tabular}

The ARIMA $(0,1,1)$ model can be written as

$y_{\tau}=\mu-\theta e_{\tau-1}+e_{\tau}$

where $y_{t}$ is the time series, $\mu$ is the intercept term, $\phi$ is the $\mathrm{AR}$ coefficient with $e_{\tau}$ being the residual or error term.

The fitted ARIMA $(0,1,1)$ model is:

$y_{t}=0.049-0.716 e_{t-1}+e_{t}$
The ACF and PACF plots of residuals belong to transformed ARIMA $(0,1,1)$ model was given Figure 7. In here, no significant autocorrelation was actual in the residuals of the fitted model.

For transformed series (ARIMA $(0,1,1)$ model) 2020-2025 cherry production forecasts was shown in Table 6. 


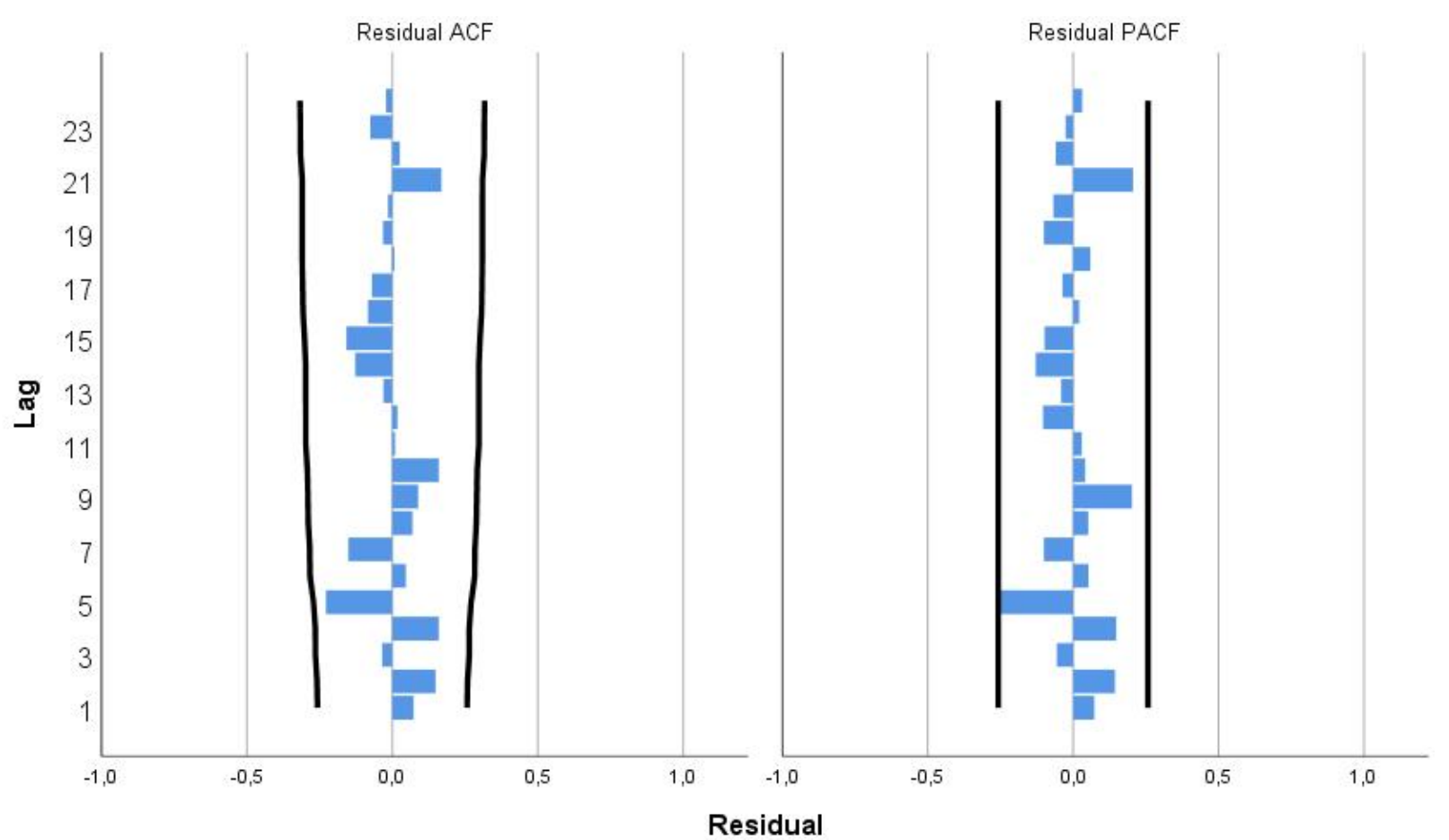

Figure 7. ACF and PACF graphs of residuals belong to transformed series

Table 6. Cherry production forecasts (in tonnes) for the period 2020-2025 in transformed series.

\begin{tabular}{lcccccc}
\hline Year & $\mathbf{2 0 2 0}$ & $\mathbf{2 0 2 1}$ & $\mathbf{2 0 2 2}$ & $\mathbf{2 0 2 3}$ & $\mathbf{2 0 2 4}$ & $\mathbf{2 0 2 5}$ \\
\hline Forecast & 696351 & 730982 & 767336 & 805498 & 845557 & 887609 \\
\hline
\end{tabular}

\section{DISCUSSION}

Within the framework of time series modeling studies, exponential smoothing and ARIMA models are remarkable tools assisting the formulation of agricultural policies. Publications on forecasting cherry production in Turkey for upcoming years are still limited in the literature. For this reason, we aimed to forecast cherry production amount in Turkey for the period 2020-2025 using the Box-Jenkins approach. The ARIMA $(1,1,1)$ model was found to be the best and our findings suggest an increase of $9.31 \%$ in 2025 in comparison to 2019. This increase was significant for sustainability of exports and domestic consumption in cherry production of Turkey. Series transformed logarithmically was modelled as $\operatorname{ARIMA}(0,1,1)$.

For the period of 2011-12 and 2023-24, Sharma et al. (2014) predicted an increase by $22.08 \%$ in apple production in Himachal Pradesh, with the help of ARIMA $(1,1,4)$ as the best model as part of Box Jenkins method. For the period 2012-2020, Celik (2013) forecasted an increase in productions of pistachio, walnut, hazelnut and almond in Turkey using various ARIMA models with different orders.
For the period 2016-2030, an increasing trend in the production of groundnut were forecasted by Celik et al. (2017) on the basis of ARIMA $(0,1,1)$ chosen as the ideal Box-Jenkins method among various ARIMA models.

An earlier study by Borkar (2016) forecasting the groundnut production in India for the period 19501951 and 2013-2014, reported that ARIMA $(0,1,1)$ model was ascertained as the ideal model. For next mandarin production amount in Turkey, an increase was forecasted by ARIMA $(0,1,2)$ model (Celik, 2019). Hossain et al. (2016) used banana production data in Bangladesh for the period 1972-2013 and forecasted the production of banana using ARIMA $(0,2,1)$ for the following years.

As regards the period 2016-2025, an upward tendency in strawberry production amounts in Turkey were forecasted by Akin and Eyduran (2017a) using Brown model as the ideal one among ARIMA $(1,1,0)$, $(1,1,1),(0,1,1)$ models as well as Holt, Brown and Damped models. An increasing trend for the 2016-2025 period was forecasted through Holt model selected as the best model among exponential smoothing models, in harvest of grape, which is of great economic importance for Turkey (Eyduran and Akin, 2017).

Selected as the best model among Brown, Damped and Holt methods, Brown exhibited an upward 
trend for avocado production in the period 2016-2025 in Turkey (Akin and Eyduran, 2017b).

An upward trend was forecasted based on Holt exponential smoothing method for the period 2016-2025 in production amounts of soybean and sunflower crops in Turkey (Karadas et al., 2017). Topuz et al. (2018) used the 1961-2016 apricot production time series with the objective to forecast the apricot production in Turkey for 2017-2022 period and reported an upward trend for the following production years within the scope of ARIMA $(2,1,1)$ model. For the period 2015-2016 to 2025-26, a downward trend in peach production of Pakistan was forecasted on the basis of ARIMA $(1,1,0)$ Box-Jenkins model (Ullah et al., 2018).

Evaluating time series data relevant to the production and banana harvest area in Turkey for the period 1961-2015, Eyduran et al. (2020) forecasted production amounts of banana for the period 2016-2025, through Brown model. Among candidate ARIMA and exponential smoothing models, Brown model showed a good fit for forecasting banana production in Turkey, and forecasted an upward trend for the period 2016-2025 (Eyduran et al., 2020).

In time series modeling of agricultural crops, ARIMA and exponential smoothing models produce reasonable results. In this regard, more sustained attention should be given to forecasting production of the crops in the future, which may aid to develop better policies.

Conclusion: The Box-Jenkins methodology was adopted to model and forecast the cherry production in Turkey. The ARIMA $(1,1,1)$ model was found to be an appropriate model for the data and the forecasts for the period 20202025 were made. Compared to the cherry production in the year 2019, cherry production in 2025 would be expected to increase by $9.31 \%$. ARIMA $(1,1,1)$ forecasts showed that cherry production amount of 664076 tonnes in 2020 would be expected to reach 726028 tonnes in 2025. The forecasts for the period 2020-2025 will reach from 696351 to 887609 tonnes in transformed series $(\operatorname{ARIMA}(0,1,1))$.

The obtained forecasts could enable policy makers to improve more effectual macro-policies for food safety and sustainability, and to improve preferable alternative cherry production strategies in Turkey to maintain its leading position in the future. Time series analysis may present significant hints about forecasting amounts produced and may facilitate formulation of successful agricultural plans in the forthcoming years.

Acknowledgements: The study was presented as an abstract at the International Congress of Vocational and Technical Sciences, UMTEB 6, 11-12 April 2019, in Iğdır in Turkey.

\section{REFERENCES}

Akın, M., and S. P. Eyduran (2017a). Forecasting Harvest Area and Production of Strawberry Using Time Series Analyses. J. Agricultural Faculty of Gaziosmanpasa University. 34(3): 18-26.

Akın, M., and S. P. Eyduran (2017b). Predicting Avocado Production in Turkey for 2016- 2025 Period Using Time Series Analysis. Yuzuncu Yil J. Agr. Sci. 27(2): 252-258.

Bal, T., and F. Cercinli (2013). The analysis of cherry production and trade in Turkey: the case of Uluborlu district. Bulg. J. Agric. Sci. 19: 398415.

Baser, U., M. Bozoğlu, N. A. Eroğlu, and B. K. Topuz (2018). Forecasting Chestnut Production and Export of Turkey Using ARIMA Model. Turkish J. Forecasting. 2(2): 27- 33.

Borkar, P. (2016). Modeling of groundnut production in India using ARIMA Model. International J. Research in IT and Management. 6(3): 36-44.

Celik, S (2013). Modelling of production amount of nuts fruit by using Box-Jenkins technique. Yuzuncu Yil J. Agr. Sci. 23(1):18-30.

Celik, S (2019). Prediction of Mandarin Production in Turkey through Artificial Neural Networks and Time-Series Analysis. International J. Trend in Research and Development. 6(5): 85-90.

Celik, S., K. Karadas, and E. Eyduran (2017). Forecastıng the Production of Groundnut in Turkey Using ARIMA Model. The J. Anim. Plant Sci., 27(3): 920-928.

Donoso, J. M., G. Lemus, D. Arribillaga, and B. Sagredo (2019). Evolution of the sweet cherry industry in Chile. Acta Hortic. 1235: 141-148. https://doi.org/10.17660/ActaHortic.2019.1235. 18

Demirsoy, H., L. Demirsoy, I. Macit, M. E. Akçay, M. Bas, I. Demirtas, C. Sarısu, Y. Taner, and A. Kuden (2017). Sweet cherry growing in Turkeya brief overview. Acta Hortic. 1161, 111-116. DOI: $\quad$ 10.17660/ActaHortic.2017.1161.19 https://doi.org/10.17660/ActaHortic.2017.1161. 19

Eyduran, S. P., and M. Akin (2017). Projecting Grape Harvest Area and Production in Turkey Using Time Series Analysis. J. Agricultural Faculty of Gaziosmanpasa University. 34(3): 64-73.

Eyduran, S. P., M. Akin, E. Eyduran, Ş. Çelik, Y. E. Ertürk, and S. Ercişli (2020). Forecasting Banana Harvest Area and Production in Turkey Using Time Series Analysis. Erwerbs- Obstbau, 62(3): 281-291. https://doi.org/10.1007/s10341020-00490-1. 
FAO, (2018). Food and Agriculture Organization of the United States. Production statistics, crops. http://www.fao.org/faostat/en/\#data/QC.

Ferretti. G., T. Bacchetti, A. Belleggia, and D. Neri (2010). Cherry antioxidants: from farm to table. Molecules. 15(10): 6993-7005. doi: 10.3390/molecules15106993

Gowri, M. U., and B. Kavitha (2016). Forecast of banana- An economic analysis. Int. J. Forestry and Crop Improv. 7(1): 132-136. DOI: 10.15740/HAS/IJFCI/7.1/132-136.

Hamjah, M. A. (2014). Forecasting major fruit crops productions in Bangladesh using Box- Jenkins ARIMA model. J. Economics and Sustainable Development. 5(7): 137-142.

Hossain, Md. M., and F. Abdulla (2015). A Time Series Analysis for the Pineapple Production in Bangladesh. Jahangirnagar Uni. J. Sci., 38(2): 49-59.

Hossain, Md. M., F. Abdulla, and A. K. Majumder (2016). Forecasting of Banana Production in Bangladesh. American J. Agri. Biological Sci., 11(2): 93- 99.

IBM Corp. Released, 2015. IBM SPSS Statistics for Windows, Version 23.0. Armonk, NY: IBM Corp.
Karadas, K., S. Celik, E. Eyduran, and S Hopoglu (2017). Forecasting production of some oil seed crops in Turkey using exponential smoothing methods. The J. Anim. Plant Sci., 27(5): 1719-1729

Pektas, A. (2013) SPSS ile veri madenciligi. Dikeyeksen Yayın Dagitim, Yazilim ve Egitim Hizmetleri San. ve Tic. Ltd. Sti.; Istanbul

Sharma, A., O. Belwal, S. K. Sharma, and S. Sharma (2014). Forecasting area and production of apple in Himachal Pradesh using ARIMA model. International J. Farm Sci., 4(4): 212-224.

Schwarz, G. E. (1978). Estimating the dimension of a Model. Annals of Statistics. 6(2): 461- 464.

TURKSTAT (2019). Turkey Statistical Institute. Crop Production Statistics. https://biruni.tuik.gov.tr/ medas/?kn=92\&locale $=$ tr

Topuz, B., M. Bozoğlu, U. Başer, and N. Eroğlu (2018). Forecasting of apricot production of Turkey by using Box-Jenkins method. Turkish J. Forecasting. 2(2): 20-26.

Ullah, A., D. Khan, and S. Zheng (2018). Forecasting of peach area and production wise econometric analysis. J. Anim. Plant Sci., 28(4): 1121-1127.

Willmott, C. J., K. Matsuura, and S. M. Robeson (2009). Ambiguities inherent in sums of squares- based error statistics. Atmos. Environ. 43:749-752. 